\title{
Research on new pavement structure in the Qinghai Tibet area
}

\author{
Mao Xuesong1, *, Huang Zhe 2 \\ ${ }^{1}$ chang'an University, Xi'an, China \\ ${ }^{2}$ chang'an University, Xi'an,China \\ *zhangwen19920510@126.com
}

Keywords: Road engineering; pavement structure; flexible base; pavement survey.

Abstract. Pavement structure directly affects the performance of the road, and the high altitude and low temperature of the Qinghai Tibet Plateau has a great influence on the pavement structure. Based on the investigation of Qinghai Tibet highway, Sichuan Tibet highway line five, summarizes the existing pavement structure types; through a comparative analysis of the pavement analysis of disease type and reason and jade high speed test of four new pavement test road. The research results show that: the four kinds of test road are better than the existing traditional semi-rigid base pavement structure in which ATB $+2 \%$ cement stabilized crushed stone base of the composite structure of the overall economic performance and performance optimization.

\section{Introduction}

In our country, the area of the permafrost area accounts for $21.5 \%$ of the land area, the seasonal frozen soil accounts for $53.5 \%$ of the total land area, it is urgent to figure out how to construct high grade highway in frozen soil area, and find a more adaptable pavement structure.

In China, the construction of highway technology research is not advance, the division of the earth from the frozen soil subgrade uneven thaw deformation, based on the previous study of the added stress of the foundation, analysis of different asphalt pavement structure of frozen soil subgrade uneven thaw deformation adaptability [1]. Zhang Xiying based on the typical pavement structure design, the disease form and the subgrade pavement structure mechanics index to establish the corresponding relationship. The typical pavement structures of the two kinds of seasonal frozen regions are presented, and the research on the technology and the economy of the two kinds of [2] is carried out. Luo Xiaodong through the indoor test of asphalt pavement in the most adverse working condition, the measured pavement structure of the basic parameters, the formulation of a typical flexible base asphalt pavement structure, and the use of software to establish finite element analysis model, the mechanical response of pavement structure under different conditions and the adaptability of flexible pavement [3]. Yin Wei through the investigation of the status of the Jilin seasonal frozen area environment, comprehensive domestic and international experience, the design index and process of asphalt pavement in seasonal frozen area was put forward and analyzed by BISAR 3.

Therefore, this paper first analyzes the adaptability of semi-rigid base pavement structure in the area of the Qinghai Tibet area, and then uses several different combination forms of flexible base course, and analyzes the performance of the new pavement structure.

\section{Investigation and analysis of pavement structure in Alpine Region}

\section{Existing pavement structure investigationr}

In the area of Tibet (Qinghai Tibet highway, Sichuan Tibet highway south line, northern Sichuan Tibet highway, Yunnan Tibet highway, Xinjiang Tibet highway and airport expressway pavement) survey found, Tibet asphalt pavement structure form in general is two kinds: $4 \mathrm{~cm}$ asphalt concrete $+5 \mathrm{~cm}$ asphalt concrete $+20 \mathrm{~cm}+20 \mathrm{~cm}$ water stabilized gravel gravel and asphalt concrete $+20 \mathrm{~cm} 4 \mathrm{~cm}$ 
water stabilized gravel $+18 \mathrm{~cm}$ natural gravel pavement structure, the conclusion is still Tibet area with semi-rigid structure as the main form, and the survey found that the road grade for the class two or three, and only the airport expressway is different from lagun semi-rigid structure of asphalt stabilized macadam + water stability gravel base composite structure, this form of play asphalt stabilized macadam deformation compatibility good, can better adapt to the permafrost areas prone to thaw deformation, reflection dissipation of semi rigid base produced by stress, and achieved good results.

\section{investigation and analysis}

The investigation and statistics of the record the pavement disease type position as shown in Table 1 shows。

\begin{tabular}{|c|c|c|c|}
\hline range of stake number & Disease situation & & \\
\hline$K 2928+500 \sim K 2931+9500$ & Pavementsubsidence Crack & & \\
\hline K2962+200 K2962+700 & Road Longitudinal crack & & \\
\hline K2994+300 K2996+900 & Uneven pavement deformation & & \\
\hline K3025+700 K3031+000 & Uneven pavement deformation & & \\
\hline$K 3073+500 \sim K 3073+800$ & Severe deformation & & \\
\hline$K 3092+350 \sim K 3093+000$ & Wave deformation & & \\
\hline K3100+800 K3100+950 & Uneven pavement deformation & & \\
\hline K3388+000 K3388+050 & $\begin{array}{l}\text { Road Longitudinal crack } \\
\text { deformation }\end{array}$ & Uneven & pavement \\
\hline$K 3138+000 \sim K 3138+500$ & Uneven pavement deformation & & \\
\hline $\mathrm{K} 3213+500 \sim \mathrm{K} 3213+700$ & Road Longitudinal crack & & \\
\hline$K 3243+450 \sim K 3243+650$ & tracing rut & & \\
\hline
\end{tabular}

On Sichuan Tibet highway pavement disease investigation result analysis found that pavement concentrated expression for crack (longitudinal seam and horizontal seam) and uneven deformation (wave, subsidence and rutting, frothing, comprehensive consideration of environmental load and pavement analysis cause of disease that:

A lot of longitudinal pavement joint is mainly due to the road slope slope phenomenon resulted in on both sides of the subgrade temperature uneven causes the frozen earth produce non-uniform melt settlement, and the road surface and the structure of semi-rigid base, the deformation coordination is very poor, a direct result of the longitudinal cracks in pavement side appear longer.

On the road there are many joints due to the pavement structure with semi rigid base structure, and the road is in the cold area, the construction period is short, the temperature changes, the traditional cement stabilized semi-rigid base under low temperature strength formation is slow, often appeared in $1 \sim 3$ years of early failure of the larger scale, in the Sichuan Tibet highway K3565+000 the survey found a shop just a year there was a lot of pavement cracks, the asphalt pavement with semi-rigid base pavement structure had different degrees of damage, and as a result of semi rigid base under temperature cycling under large grass dry shrinkage and temperature shrinkage phenomenon is difficult to avoid, inevitably produce reflection cracks, caused by surface damage the transverse cracks in the pavement damage. And once the pavement surface layer cracks, rainfall and snowmelt will make the water into the interior of the pavement structure, coupled with the semi-rigid pavement structure drainage itself is poor, water into the pavement structure is difficult to discharge and then enriched by, under temperature cycling and traffic load of comprehensive cooperation with the road pumping mud, frost heaving, frost and other diseases and difficult maintenance repair, often appear a vicious cycle of damage repair damage - repair. 
It is found that the deformation of the pavement is sensitive to the deformation of the pavement structure, and it is found that the surface of the pavement is not suitable for the frozen soil area, and it is found that the pavement is not suitable for the frozen soil area。

\section{new pavement structure test road paving}

\section{test road and test pavement structure}

The test section was chosen in the first phase of the project of the Yushu (ancient) highway, the B3 contract section, the pile number is K632+000-K634+200. The road has an average altitude of 4600 meters, flat terrain, rapid temperature changes, more summer precipitation and surface area covering $20 \sim 30 \mathrm{~cm}$ meadow soil, and the lower part is the silt or silty gravel soil engineering properties is poor, the massive swamp development, serious ground water, the local area are due to thaw lakes formed. This section of the frozen soil development, the natural frozen soil is about $2.6 \mathrm{~m}$, the artificial frozen soil limit reached $5.4 \sim 6.9 \mathrm{~m}$, the maximum water content is $57.27 \%$, the average water content is $90.33 \%$.

Test road as a whole by flexible pavement structure, combined with the actual situation of local heavy traffic volume, road test design a variety of new pavement structure by geocell reinforcement of graded crushed stone or Graded Macadam flexible base base +ATB-25 asphalt stabilized gravel base asphalt pavement and mining with contrasting sections of the cement stabilized macadam base test road concrete forms and origin of pile, see Table 2

\begin{tabular}{lll}
\hline Stake Number & $\mathrm{K} 632+000 \sim \mathrm{K} 633+200$ & $\mathrm{~K} 633+200 \sim \mathrm{K} 634+200$ \\
\hline Above Layer & $4 \mathrm{~cm} \mathrm{AC}-13 \mathrm{C}$ & $4 \mathrm{~cm} \mathrm{AC}-13 \mathrm{C}$ \\
lower layer. & $5 \mathrm{~cm} \mathrm{AC}-16 \mathrm{C}$ & $5 \mathrm{~cm} \mathrm{AC}-16 \mathrm{C}$ \\
Pavement base & $18 \mathrm{~cm} \mathrm{ATB}-25$ & $18 \mathrm{~cm}$ ATB-25 \\
& $18 \mathrm{~cm}$ Graded broken stone & $\begin{array}{l}18 \mathrm{~cm} \text { Graded broken stone reinforced } \\
\text { with soil engineering }\end{array}$ \\
\hline
\end{tabular}

\section{test road performance test}

Through the use of Backman beam method to test the test road section (total jade high speed K629+800 K634+200 test section and the section of the production section), see Table 3

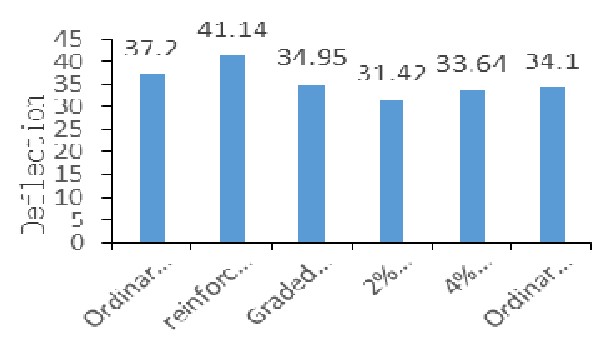

\section{new pavement structure adaptability analysis}

Through the comprehensive analysis of the test section and the production section of the road surface of the average deflection and bending Lr, and pavement distress survey results can be obtained the following conclusions:

(1) graded k632+000 (k633+200) and k633+200 (K634+200), the most of the pavement deflection is the biggest, the pavement deflection is moderate; the $2 \%$ water stable graded $\mathrm{k} 630+800(\mathrm{k} 632+000)$ and $4 \%$ water stabilized gravel $(\mathrm{k} 629+800 \sim \mathrm{k} 630+800)$ section is the smallest.

(2) by the pavement structure, the pavement structure of the production section and the bottom layer are semi-rigid structure; the pavement base of the test section is ATB - 25, and the bottom level is divided into $2 \%$ water stable graded crushed stone, the semi rigid structure and the graded broken stone, and the flexible structure of the soil. Based on the results of Table 1, it can be known that the 
rebound deflection of semi-rigid base asphalt pavement is significantly less than that of flexible base asphalt pavement. But according to the survey results of this road disease, the ATB - 25 flexible base asphalt pavement cracks, and the deformation of asphalt mixture is not sensitive to water, and the water and ice are not sensitive to water, and the deformation is small, and the reflection cracks and low temperature cracks are avoided.

(3) from table $2 \%$ we can know that the 1 water stabilized gravel $(\mathrm{k} 630+800 \sim \mathrm{k} 632+000)$ section is less than $4 \%$ water stable $\mathrm{k} 629+800(\mathrm{k} 630+800)$, the former has a good structural deformation and low cement dosage, which can save the construction cost and improve economic efficiency.

\section{Conclusion}

1.The traditional single semi-rigid base pavement has been unable to meet the requirements of the road construction in the future. In the frozen soil area, the surface of the frozen soil area is not adaptive, which is reflected in the more horizontal cracks, vertical cracks and large uneven deformation.

2.The pavement with flexible structure is very good, and the pavement damage is reduced by a lot of pavement damage.

3.ATB flexible base + soil engineering grid reinforcement of the bottom of the base layer of the structure, although the theory should have better performance due to the construction technology is not mature, the construction environment is complex and can not achieve good results.

4 grading of ATB+ gravel at the bottom of the base structure bending sink larger bearing capacity with respect to the semi rigid base structures are small, practical application need to increase the thickness of the surface layer to ensure the bearing capacity of the high cost.Fifthly, ATB flexible base $+2 \%$ water stable macadam structure in the test bending heavy small, less disease and relative amount of cement less has better adaptability and economy.

\section{References}

[1] Si Wei. Research on asphalt pavement structure adaptability and durability in permafrost regions [D]. Chang'an University, 2011

[2] Zhang Xiying. The typical pavement structure of the seasonal frozen area based on the full life cycle [D]. Jilin University, 2013

[3] Luo Xiaodong. Adaptability of flexible base asphalt pavement in seasonal frost area [D]. Chang'an University, 2012

[4] Ji Yang Peiyi, Ma Biao, Wang Bing gang. Subgrade in permafrost regions financial settlement deformation of asphalt pavement structure [J]. China Journal of highway, 2006, Vol. 5 (5): 1-5.

[5] Zhang Yanhong, Shen Aiqin, Guo Yinchuan, et al. Comparison and analysis of mechanical response of asphalt pavement structure of three kinds of asphalt pavement [J]. Journal of Chang'an University: Natural Science Edition, 2009, Fourth: 1-7.

[6] fan Yin. The cement concrete pavement in permafrost area of Chang'an University [D]. failure mode and structure reliability, 2012

[7] Mu Yanhu, Ma Wei, Niu Fujun, et al. Research on the types and characteristics of road engineering disease in permafrost regions $[\mathrm{J}]$. Journal of disaster prevention and reduction engineering, 2014, 03.

[8] Yu Qihao, Fan Kai, Qian Jin, et al. Research on key issues of highway construction in permafrost regions in China [J]. China Science: technology science, 2014, 04 (4): 425-432.

[9] Gao Ming, Li Xiangquan, Wang Zhenxing, et al. The cause and prevention of highway disease in Alpine permafrost regions [J]. highway, 07, 2014.75-77. 